\title{
Healthcare Professionals' Perceptions of Non-Communicable Diseases Risk Factors and Its Regional Distribution in Ethiopia
}

\author{
Melkamu D. Kassa ${ }^{1} \&$ Jeanne Grace ${ }^{1}$ \\ ${ }^{1}$ Discipline of Biokinetics, Exercise \& Leisure Sciences, University of KwaZulu-Natal, Durban, South Africa \\ Correspondence: Melkamu Kassa, Discipline of Biokinetics, Exercise \& Leisure Sciences, University of \\ KwaZulu-Natal, Durban 4000, South Africa. Tel: 27-74-749-8380. E-mail: kassa2015@gmail.com
}

Received: October 16, 2017 Accepted: November 20, 2017 Online Published: December 1, 2017

doi:10.5539/gjhs.v10n1p88 URL: https://doi.org/10.5539/gjhs.v10n1p88

\begin{abstract}
Introduction: Non-communicable diseases (NCDs) are increasing as the main cause of death, disability, unproductivity and indisposition in Ethiopia.
\end{abstract}

Objectives: The objectives of this study were to establish healthcare professionals' perception on non-communicable disease risk factors and their regional distribution in Ethiopia.

Methods: A mixed method sequential explanatory design was conducted with a questionnaire survey obtaining quantitative replies from 312 healthcare professionals working in 13 referral hospitals in the first phase and qualitative data among 13 hospital managers in the second phase.

Results: Statistically significant prevalence of NCDs risk factors were reported with the lack of physical exercise $(\mathrm{M}=4.94, \mathrm{SD}=.245, \mathrm{t}(311)=139.383 ; p<.0005)$, hypertension $(\mathrm{M}=4.89, \mathrm{SD}=.312, \mathrm{t}(311)=107.021 ; p<.0005)$, and unhealthy $\operatorname{diet}(\mathrm{M}=4.61, \mathrm{SD}=.782, \mathrm{t}(311)=36.426 ; p<.0005)$ ranking as the top three leading NCDs risk factors. The prevalence and distribution of NCDs risk factors varied within Ethiopia, with a high perceived prevalence of lack of physical exercise, unhealthy diet, alcohol use, and blood glucose in Addis Ababa city followed by Amhara region. A high prevalence of tobacco use and hypertension was also observed in the regions of Benishangul Gumuz.

Conclusion: The results revealed that the prevalence of NCDs risk factors are increasing in different regions of Ethiopia. Regionally specific non-communicable disease intervention strategies are required to revert the growing burden of the risk factors effectively.

Keywords: hypertension, non-communicable diseases, physical exercise, tobacco use, unhealthy diet

\section{Introduction}

Non-communicable diseases (NCDs) such as cancer, hypertension, diabetes, and cardiovascular diseases appear to be the main cause of death, disability, lost productivity and indisposition globally (Bhattacherjee, Datta, Roy, \& Chakraborty, 2015; Chaker et al., 2015). Studies have shown that rapid urbanization and industrialization are responsible for the growing burden of NCDs (Kraja et al., 2016; Peykari et al., 2017) and results in lifestyle changes and an epidemiological transition (Raghavendra Swamy Koppad, 2014). Statistics indicate that NCDs are associated with $85 \%$ of premature mortality in 2012 , specifically in low- and middle-income countries (World Health Organization, 2014).

The major NCDs share collective roots, these categorized as behavioral, physical and biological risk factors. The behavioral risk factors include unhealthy diet, tobacco use, lack of physical exercise and alcohol use; physical risk factors include hypertension (blood pressure), overweight and obesity; and biological risk factors, are blood glucose and hypercholesterolemia (Chhaya, Devalia, \& Kedia, 2015). In terms of attributable deaths, the leading six NCDs risk factors are raised blood pressure (accountable for 13\% of global deaths), followed by tobacco use $(9 \%)$, raised blood glucose $(6 \%)$, physical inactivity $(6 \%)$, alcohol use $(5.9 \%)$ and overweight/obesity (5\%) (World Health Organization, 2014). The distribution of NCDs risk factors varies among countries and regions, and while often perceived as the diseases of industrialized nations, their burden is rising in low- and middle-income countries, such as those in the Pacific region (Hou, Anderson, \& Burton-Mckenzie, 2017). South East Asia (Zhang, 2014) and sub-Saharan Africa (SSA) (Atiim \& Elliott, 2016). The prevalence of hypertension varies among countries, with the lowest prevalence of $3.4 \%$ in Indian men, to the highest $72.5 \%$ in Poland and $78 \%$ in South Africa 
(Lloyd-Sherlock, Beard, Minicuci, Ebrahim, \& Chatterji, 2014).

NCDs account for $34 \%$ of the annual total deaths in Ethiopia (World Health Organization, 2013) with a study in the south west (Asgedom, Gudina, \& Desse, 2016) indicating the growing prevalence of risk factors, such as physical inactivity (17\%), unhealthy diet (27\%), hypertension (9.3\%), smoking (9\%), blood glucose (8\%) and alcohol consumption $(7.3 \%)$. A cross-sectional community based study in East Gojam zone, Ethiopia, showed the prevalence of blood glucose $(13.4 \%)$ to be higher in urban than in rural areas $(10.3 \%)$ (Wondemagegn, Hbizuayehu, Abie, Ayalneh, \& Tiruye, 2017). Small area community based assessments were conducted to determine the prevalence of NCDs risk factors in Ethiopia. Most of these studies were conducted on the prevalence of hypertension, with the results showing a prevalence of $28 \%$ in the town of Arba Minch (Helelo, Gelaw, \& Adane, 2014), 45.8\% in Adama City (Anuwer et al., 2015), 27.3\% in the capital city of Addis Ababa (Angaw, Dadi, \& Alene, 2015), 19.8\% in Bahir Dar City (Anteneh, Awoke, \& Birhanu, 2015), 28\% in northwest Ethiopia (Abebe, Berhane, Worku, \& Getachew, 2015), and 50.3\% in south west Ethiopia (Asgedom et al., 2016). A hospital based mortality study in Addis Ababa showed that $31 \%$ of annual deaths were attributed to NCDs (Misganaw, Mariam, Araya, \& Ayele, 2012).

Considerable effort has been made to project the anticipated health burden of NCDs in many countries, with little progress in Ethiopia due to a limited understanding of the country-specific risk factors. Despite the growing burden of NCDs, there is limited information on the prevalence and regional distribution of NCDs risk factors within Ethiopia, and on the perception of healthcare professionals' about these risk factors, this being important to help policy makers to establish appropriate interventions in affected areas. This study therefore aims to establish healthcare professionals' perceptions on the prevalence and regional distribution of NCDs risk factors in Ethiopia.

\section{Materials and Methods}

\subsection{Study Design}

A mixed research method, explanatory sequential design was conducted at 13 purposively selected Ethiopian hospitals that provides tertiary healthcare for NCDs.

\subsection{Location and Participants}

The study was conducted in 13 referral hospitals in five regions in Ethiopia: Addis Ababa City, and the regions of Amhara, Benishangul, Oromia, and Southern Nationalities. The study consisted of two phases, the first being a questionnaire survey of 312 healthcare professionals' who were proportionately and randomly selected from the 13 hospitals, and the second entailing interviews of 13 hospital managers who were purposively selected to establish their understanding of the NCDs risk factors. Participants were considered for inclusion if they had three years and more work experience in a hospital treating NCDs related conditions.

\subsection{Data Collection Procedures}

A self-administered questionnaire was developed after being piloted to ensure validity and reliability. The validity of the questionnaire was also checked by a biostatistician before the data collection commenced. For the questionnaire items, using the standard cut-off point (alpha $=0.05$ ), a Cronbach's Alpha 0.776 was obtained.

During the first phase of data collection, healthcare professionals' who consented in writing to participate and fulfilled the inclusion criteria completed the questionnaire. It consisted of two sections, the first enquired about their demographic characteristics, and the second established their perceptions on the prevalence and regional distribution of six NCDs risk factors (Alcohol, unhealthy diet, lack of physical exercise, tobacco use, blood glucose, and hypertension). Participants were requested to rate their perceptions on a 5-point Likert scale ranging from "very low" (1) to "very high" (5) for each condition for all included regions. A trained fieldworker administered the questionnaires to the selected healthcare workers. In the second phase, an interview session was scheduled with 13 hospital managers to investigate their personal opinion on the predictors of NCDs risk factors.

\subsection{Statistical Analysis}

The phase 1 quantitative data were cleaned, coded and analyzed using the Statistical package for Social Science (SPSS) version 24. Descriptive statistical analysis was performed to illustrate the socio-demographic characteristics of the participants. The perceived NCDs risk factors were statistically analyzed to establish the mean and standard deviation, and a sample t-test was applied to identify their mean difference and ranking. Frequency tables were used to indicate the perceived degree of NCDs risk factors. One-way ANOVA F-test and Post Hoc Tukey HDS multiple comparison of mean was used to determine the perceived distribution of NCDs risk factors among the regions. All tests were conducted to show a $95 \%$ confidence intervals and to recognize a $5 \%$ level of significance. All means were considered significantly different at $p<0.05$. For the qualitative analysis in 
phase 2, information obtained from the interviews were transcribed and transferred into the Nvivo11 software package, where the data was thematically analyzed.

\subsection{Ethical Considerations}

This study was approved by the local institutional biomedical research and ethics committee according to the principles of the Declaration of Helsinki. (Reference number: HSS/0683/015D). Permission to conduct the study was obtained from the Ethiopian Ministry of Health.

\section{Results}

\subsection{Phase 1-Quantitative Component}

The general characteristics of the participants are illustrated in Table 1. The results showed that almost two thirds of the respondents were male $(195,62.5 \%)$, with most being $27-33$ years of age $(58.0 \%)$ and married $(255,81.7 \%)$. Two thirds of the participants were general nurses $(209,67.0 \%)$, while a greater number of physicians were general physicians $(72,23.1 \%)$. Over half had 3-8 service years $(57.4 \%)$ with only a few $(8,4.2 \%)$ having $15-20$ years of service and health team managers $(12,3.8 \%)$.

Table 1. Characteristics of the respondents ( $\mathrm{N}=312)$

\begin{tabular}{llllll}
\hline Characteristics & $\mathbf{n}$ & $\mathbf{\%}$ & Characteristics & $\mathbf{n}$ & $\mathbf{\%}$ \\
\hline Gender & & & Specialization & & \\
Male & 195 & 62.5 & Specialist physician & 17 & 5.4 \\
Female & 117 & 37.5 & General physician & 72 & 23.1 \\
Age group & & & Health team manager & 12 & 3.8 \\
$20-26$ & 5 & 1.6 & General nurse & 209 & 67.0 \\
$27-33$ & 181 & 58.0 & Clinical nurse & 2 & 0.6 \\
$34-40$ & 107 & 34.3 & Years' service & & \\
$41-46$ & 19 & 6.1 & $3-8$ & 179 & 57.4 \\
Marital status & & & $9-14$ & 120 & 38.5 \\
Single & 57 & 18.3 & $15-20$ & 13 & 4.2 \\
Married & 255 & 81.7 & & & \\
\hline
\end{tabular}

The results of the perceived ranking of NCDs risk factors (Table 2) were statistically significant, with a lack of physical exercise $(\mathrm{M}=4.94, \mathrm{SD}=.245, \mathrm{t}(311)=139.383, p<0.0005)$ being highest, followed by hypertension $(\mathrm{M}=4.89, \mathrm{SD}=.312, \mathrm{t}(311)=107.021, p<.0005)$ and an unhealthy diet $(\mathrm{M}=4.61, \mathrm{SD}=.782, \mathrm{t}(311)=36.43, p<$ $0.0005)$, while blood glucose $(\mathrm{M}=3.41, \mathrm{SD}=1.0, \mathrm{t}(311)=7.241, p<.0005)$ was ranked the lowest.

Table 2. Ranking of NCD risk factors based on the mean

\begin{tabular}{|c|c|c|c|c|c|}
\hline NCDs risk factor & Mean & SD & $\begin{array}{l}\text { One sample } \\
\text { t-test }\end{array}$ & $p$-value & $\begin{array}{l}\text { Mean } \\
\text { Difference }\end{array}$ \\
\hline 1. Lack of physical exercise & 4.94 & .245 & 139.383 & .000 & 1.936 \\
\hline 2. Hypertension & 4.89 & .312 & 107.021 & .000 & 1.891 \\
\hline 3. Unhealthy diet & 4.61 & .782 & 36.426 & .000 & 1.612 \\
\hline 4. Alcohol use & 3.58 & 1.25 & 8.244 & .000 & 0.583 \\
\hline 5. Tobacco use & 3.51 & 1.213 & 7.418 & .000 & .510 \\
\hline 6. Blood glucose & 3.41 & 1.001 & 7.241 & .000 & .410 \\
\hline
\end{tabular}

The healthcare workers perceptions about the prevalence of NCD risk factors are displayed in Table 3 , with the highest being lack of physical exercise $(93.6 \%, p<.0005)$, hypertension $(89.1 \%, p<.0005)$, and unhealthy diet 
$(79.8 \%, p<.0005)$.

Table 3. Perceived prevalence of NCDs risk factors $(\mathrm{N}=312)$

\begin{tabular}{lllllll}
\hline \multirow{2}{*}{ NCDs risk factors } & \multicolumn{2}{l}{ Prevalence Scales } & \\
\cline { 2 - 5 } & $\begin{array}{l}\text { Very low } \\
\mathbf{n}(\%)\end{array}$ & $\begin{array}{l}\text { Low } \\
\mathbf{n}(\%)\end{array}$ & $\begin{array}{l}\text { Medium } \\
\mathbf{n}(\%)\end{array}$ & $\begin{array}{l}\text { High } \\
\mathbf{n}(\%)\end{array}$ & $\begin{array}{l}\text { Very high } \\
\text { n (\%) }\end{array}$ & p-value \\
\hline Lack of physical exercise & $0(0.0)$ & $0(0.0)$ & $0(0.0)$ & $20(6.4)$ & $292(93.6)$ & .000 \\
Hypertension & $0(0.0)$ & $0(0.0)$ & $0(0.0)$ & $34(10.9)$ & $278(89.1)$ & .000 \\
Unhealthy diet & $0(0.0)$ & $0(0.0)$ & $58(18.6)$ & $5(1.6)$ & $249(79.8)$ & .000 \\
Alcohol use & $22(7.1)$ & $43(13.8)$ & $74(23.7)$ & $77(24.7)$ & $96(30.8)$ & .000 \\
Tobacco use & $21(6.7)$ & $44(14.1)$ & $85(27.2)$ & $79(25.3)$ & $83(26.6)$ & .000 \\
Blood glucose & $0(0.0)$ & $66(21.2)$ & $104(33.3)$ & $90(28.8)$ & $52(16.7)$ & .000 \\
\hline
\end{tabular}

The results on the regional distribution of alcohol abuse as a NCD risk factor in Table 4 indicate that Addis Ababa (AA) is regarded as having a significantly higher prevalence of alcohol use than in the Oromia (OR) $(p<.0005)$ and Southern nations and nationalities (SNNP) region $(p<.0005)$. Amhara (AM) region has a higher perceived prevalence than OR $(p<.0005)$ and SNNP regions $(p<.0005)$. Benishangul Gumuz $(\mathrm{BG})$ region has a higher perceived prevalence than the OR $(p<.0005)$ and SNNP regions $(p=.004)$.

The perceived prevalence of unhealthy diet as indicated in Table 4 is significantly higher in AA region than AM ( $p$ $<.0005)$, BG $(p<.0005)$, OR $(p<.0005)$ and SNNP regions $(p<.0005)$. It is also significantly higher in AM region than the OR $(p<.0005)$ and SNNP Regions $(p<.0005)$. There is a significant higher perceived prevalence of lack of physical exercise in AA than in the AM $(p<.0005)$, BG $(p<.0005)$, OR $(p<.0005)$ and SNNP regions $(p<.0005)$. It was also perceived to be significantly higher in AM region than in BG region $(p=.004)$, in OR region than $\mathrm{BG}(p<.0005)$ and SNNP regions $(p<.0005)$. (Table 4)

The results showed a significant higher perceived prevalence of tobacco use in $\mathrm{BG}$ region than $\mathrm{AA}(p=.027)$, AM $(p<.0005)$, OR $(p<.0005)$, and the SNNP regions $(p<.0005)$. A significant higher disparity in tobacco use was observed in AA region than OR $(p<.0005)$, and SNNP region $(p=.007)$, and in AM than OR region $(p=.005)$. As indicated in Table 4, a significant higher perceived prevalence of blood glucose is reported in AA region than the other four regions $(p<.0005)$. It is also found significantly higher in AM than BG region $(p<.005)$, OR than BG region $(p<.0005)$, and SNNP region than BG region $(p<.0005)$. The results revealed a significant higher perceived prevalence of hypertension reported in $\mathrm{BG}$ region than $\mathrm{AM}(p=.005)$, OR region than $\operatorname{AM}(p<.0005)$, SNNP region than $\mathrm{AM}(p<.0005)$, and AA region $(p=.002)$.

Table 4. Perceived Regional distribution of NCD risk factors

\begin{tabular}{|c|c|c|c|c|c|}
\hline Risk factor & (I) Region & $\begin{array}{l}\text { (J) Regional } \\
\text { distribution }\end{array}$ & $\begin{array}{l}\text { (I-J) Mean } \\
\text { difference }\end{array}$ & Std. Error & p-value \\
\hline \multirow{10}{*}{ Alcohol use } & Addis Ababa & AA & .363 & .160 & .156 \\
\hline & & BG & .216 & .226 & .875 \\
\hline & & OR & $1.599 *$ & .142 & .000 \\
\hline & & SNNP & $1.098^{*}$ & .187 & .000 \\
\hline & Amhara & $\mathrm{BG}$ & -.148 & .230 & .968 \\
\hline & & OR & $1.236^{*}$ & .148 & .000 \\
\hline & & SNNP & $.734 *$ & .192 & .001 \\
\hline & Benishangul & OR & $1.383^{*}$ & .218 & .000 \\
\hline & & SNNP & $.882 *$ & .250 & .004 \\
\hline & Oromia & SNNP & $-.501 *$ & .177 & .040 \\
\hline
\end{tabular}




\begin{tabular}{|c|c|c|c|c|c|}
\hline & Addis Ababa & $\mathrm{AM}$ & $.818^{*}$ & .168 & .000 \\
\hline & & BG & $1.370^{*}$ & .238 & .000 \\
\hline & & OR & $1.704 *$ & .150 & .000 \\
\hline \multirow[t]{9}{*}{ Unhealthy diet } & & SNNP & $1.782 *$ & .197 & .000 \\
\hline & Amhara & BG & .551 & .242 & .156 \\
\hline & & OR & $.886^{*}$ & .156 & .000 \\
\hline & & SNNP & $.964^{*}$ & .202 & .000 \\
\hline & Benishangul & OR & .334 & .230 & .593 \\
\hline & & SNNP & .412 & .263 & .519 \\
\hline & Oromia & SNNP & .078 & .187 & .994 \\
\hline & Addis Ababa & $\mathrm{AM}$ & $1.460^{*}$ & .160 & .000 \\
\hline & & BG & $2.285^{*}$ & .226 & .000 \\
\hline \multirow[t]{11}{*}{ Lack of physical exercise } & & OR & $1.078^{*}$ & .142 & .000 \\
\hline & & SNNP & $1.814^{*}$ & .187 & .000 \\
\hline & Amhara & $\mathrm{BG}$ & $.825^{*}$ & .230 & .004 \\
\hline & & OR & -.382 & .148 & .077 \\
\hline & & SNNP & .354 & .192 & .348 \\
\hline & Benishangul & OR & $-1.207 *$ & .218 & .000 \\
\hline & & SNNP & -.470 & .250 & .327 \\
\hline & Oromia & SNNP & $.736^{*}$ & .177 & .000 \\
\hline & Addis Ababa & $\mathrm{AM}$ & .392 & .173 & .158 \\
\hline & & BG & $-.724^{*}$ & .245 & .027 \\
\hline & & OR & $.951 *$ & .154 & .000 \\
\hline \multirow[t]{10}{*}{ Tobacco use } & & SNNP & $.685^{*}$ & .202 & .007 \\
\hline & Amhara & BG & $-1.117^{*}$ & .249 & .000 \\
\hline & & OR & $.559 *$ & .161 & .005 \\
\hline & & SNNP & .293 & .208 & .622 \\
\hline & Benishangul & OR & $1.676^{*}$ & .236 & .000 \\
\hline & & SNNP & $1.409^{*}$ & .270 & .000 \\
\hline & Oromia & SNNP & -.266 & .192 & .636 \\
\hline & Addis Ababa & $\mathrm{AM}$ & $.783 *$ & .117 & .000 \\
\hline & & BG & $2.086^{*}$ & .165 & .000 \\
\hline & & OR & $.981 *$ & .104 & .000 \\
\hline \multirow[t]{7}{*}{ Blood glucose } & & SNNP & $1.152^{*}$ & .137 & .000 \\
\hline & Amhara & BG & $1.304 *$ & .168 & .000 \\
\hline & & OR & .198 & .108 & .360 \\
\hline & & SNNP & .369 & .140 & .066 \\
\hline & Benishangul & OR & $-1.106^{*}$ & .159 & .000 \\
\hline & & SNNP & $-.934 *$ & .182 & .000 \\
\hline & Oromia & SNNP & .172 & .130 & .676 \\
\hline
\end{tabular}




\begin{tabular}{llllll}
\hline & Addis Ababa & AM & .296 & .126 & .131 \\
& & BG & -.335 & .178 & .327 \\
Hypertension & OR & -.219 & .112 & .288 \\
& & SNNP & $-.553^{*}$ & .147 & .002 \\
\cline { 2 - 6 } & Amhara & BG & $-.631^{*}$ & .181 & .005 \\
& OR & $-.515^{*}$ & .117 & .000 \\
\cline { 2 - 6 } & Benishangul & OR & $-.848^{*}$ & .151 & .000 \\
\hline
\end{tabular}

Note. $* \mathrm{p}<0.05$

$\mathrm{AA}=$ Addis Ababa city, $\mathrm{AMR}=$ Amhara region, $\mathrm{BGR}=$ Benishangul Gumuz region, $\mathrm{OR}=$ Oromia region, $\mathrm{SNNPR}=\mathrm{Southern}$ nations and nationalities region.

\subsection{Phase 2 - Qualitative Results}

Questions regarding the top three NCDs risk factors identified in Phase 1 (unhealthy diet, lack of physical exercise and hypertension) were used in the interviews and focus group discussions with the hospital managers to obtain their opinions regarding the major NCDs risk factors in Ethiopia.

Q1. What are the lack of physical exercise related risk factors for NCDs? Which aspects of physical exercise contribute to NCD?

The focus group discussants highlighted inadequate physical exercise to be a risk factor for NCDs:

"...inadequate regular physical exercise can be the main NCDs risk factor in our country, due to the fact that the participation of adults and the elderly in physical exercise is poor throughout the country. Motivation to partake in physical exercise is lacking in the community, schools and work places. ...participating in physical exercise is perceived as fruitless and wasting of school, study and work time by the community."

“...the case of physical exercise is a serious issue. Adolescents spent their time after school in restaurants by drinking alcohol or chewing tobacco. The physical education curriculum in schools from grade one up to university level is not up to standard. The time allotted for the physical education program in schools is 40 minutes per week, which is not enough when compared to the WHO recommendations on physical activity."

\section{Q2. What are the risk factors of NCDs associated with hypertension?}

The respondents' reported that situation, social class, current health status, and age were the contributing factors to hypertension in Ethiopia. "Situation: gradually, unhealthy lifestyle choices, like lack of physical exercise and poor diet, can take their toll on your body. Lifestyle choices can lead to weight problems. Being overweight or obese can increase your risk for hypertension. Social class: the difference in social class is the predictor of hypertension. It is common in our country to see peoples with high income are more sedentary, overweight, consume energy dense foods like cakes and burgers, raw meat "Qurt siga", spiced butter "Niter kibe", heavy alcohol, tobacco and foods with excess salt. Current health status: the existing cardiovascular disease, high level cholesterol, and diabetes are the predictors of hypertension, particularly with increasing age."

\section{Q3: What are the diet related risk factors of NCDs? Which aspects of diet contributes to it being perceived as a NCD?}

The responders stated that the poor quality of the Ethiopian's diet was a major NCD risk factor in the country's healthcare setting.

"...frequent use of unhealthy low quality crude cooking oil (HAYAT), raw beef, lamb and goat meat, use of spiced butter, excess salt intake and lack of fruit in daily diet are the risk factors of NCDs. The fact is that the majority of the public do not have understanding of the diseases associated with excessive salt intake, fruits and vegetable deficiency. Fruits are consumed less frequently and may be due to a low access and supply on the market."

Moreover, the participants stated that diet related risk factors of NCDs are associated with cultural and social norms. 
“...people with fatter bodies have public acceptance compared to individuals with slimmer bodies in the Ethiopian culture. The majority of the public perceive that people who are fat with bulged stomachs are wealthier, healthy, and charismatic than individuals with a slim body appearance. This fact make most people to consume foods and drinks that increase their body size, especially abdominal fat. Eventually people develop NCDs like cardiovascular disease, diabetes, hypertension and cancer."

The focus group discussants also noted the cultural perception of people with slim bodies.

“...people with a slim body appearance are perceived as the poorest, inferior, guilty, unproductive, sinful, weak, hopeless, cursed and rude. The public worship fat bodies and disregard slim bodies. Such perceptions of the population are the drivers to have an unhealthy diet, like animal fats and facilitate the onset of major NCDs in the community. So, do you think that culture is not a risk factor for NCDs? For me, definitely."

\section{Q4. How do you perceive the public's awareness on NCDs risk factors?}

Lack of understanding and awareness are also stated as a NCDs risk factor in Ethiopia.

“...information is the guide that enables individuals, health care providers and leading organization to make quick decisions. An informed individual about the causes and burden of disease will assist the individual in preventing him/herself or families from NCDs related risk factors. Uninformed people are more exposed to diseases than informed people. Also, lack of awareness among the public increases the burden of NCDs and its related risk factors."

All focus group discussants indicated tobacco use, including the chewing of tobacco, excessive alcohol drinking, as additional risk factors in Ethiopia.

“...the number of breweries are increasing dramatically. Major social media's (radio and television) are advertising alcoholic products regularly several times a day. This advertisements on alcohol results in cost reduction, which in turn leads to an individual's chance of purchasing alcohol products at a low cost. Consuming of the local alcohol product ('Arakie') is responsible for hypertension and liver cancer. ...also, the government is manufacturing tobacco and cigarettes. Tobacco products can be purchased from the market or self-prepared, and chewing of tobacco are all risk factors for NCDs."

\section{Discussion}

This study aimed to establish healthcare professionals' perceptions on the ranking, prevalence and regional distribution of NCDs risk factors in Ethiopia. The results of the two phases of the study were integrated, and the results of Phase 1 was substantiated by the responses from Phase 2 .

A significant number of participants (93.6\%) indicated a lack of physical exercise to be the major perceived risk factors for NCDs in Ethiopia. This was supported by the results of the qualitative study, which revealed that public attitude and governmental policy contribute to the lack of physical exercise. The qualitative results are consistent with other studies that indicate negative attitude (Amireault, Godin, \& Vézina-Im, 2013), lack of awarness on the health benefits of physical exercise (Duncan et al., 2014), and lack of infrastucture (Goodman, Sahlqvist, \& Ogilvie, 2014) that enables physical exercise participation as being responsible for its high prevalence. The result of our study on pereceived prevalance of lack of physical exercise is higher than the finding in Uganda of 51\%, which can be attributed to the diferences in the study setting, participants and the terminologies used in the study, such as physical exercise and physical activity (Mondo, Otim, Akol, Musoke, \& Orem, 2013).

The perceived prevalence of $89.1 \%$ of hypertension in our study is much higher than the $27.3 \%$ found by a study in Addis Ababa (Angaw et al., 2015), 16.9\% in southwest Ethiopia (Gudina, Bonsa, Gudina, \& Hajito, 2014), 17\% in Tanzania and $19 \%$ in Uganda (Kavishe et al., 2015). The difference could be attributed to study populations, with this study exploring the perceptions of healthcare providers' nationwide, while the previous studies were on members of the public living in specific locations. The results of this study showed a $79.8 \%$ perceived prevalence of unhealthy diet, which is lower than the $93 \%$ reported in Bangladesh (Zaman et al., 2015). The difference might be attributed to geographical location, cultural norms and food habits. In Ethiopia, the perceived prevalence of an unhealthy diet was high due to the limited availability of fruit, with fruit and vegetables being considered as the meal of patients or people who are ill. The public's desire to maintain a high body fat, and the frequent eating of animal fats to develop a big stomach, are contributors to an unhealthy diet, as indicated in the interviews with the hospital managers.

The perceived prevalence of alcohol abuse (30.8\%), tobacco use (26.6\%) and blood glucose $(16.7 \%)$ were lower compared to the other NCD risk factors. However, there are a growing number of breweries in the country, and therefore increased alcohol supply countrywide. In addition, Ethiopia produces more than 25 types of local liquor 
called 'Arakie', which is the major cause of liver cancer and hypertension, according to the interviews with the hospital managers. While other countries attempt to reduce tobacco usage, the National Tobacco Enterprise (NTE), a company owned by the government, is increasing its production of cigarettes from 4 billion to 6 billion a year. While other World Health Organization affiliated nations are implementing an increase in tobacco and alcohol taxes to discourage consumption, Ethiopian policy makers are not following suite, which contributes to worsening tobacco use.

The present study indicates a statistically significant difference in the perceived prevalence of NCDs risk factors among the Ethiopian regions. The regional distribution of alcohol abuse was perceived to be higher in Addis Ababa (AA) than other regions, due possibly to most breweries being located in and around the city, which may result in a higher public access compared to other regions. This is consistent with a Chinese study that demonstrated the regional disparity of drinking among residents who live in area where the production of alcohol is high compared to other regions ( $\mathrm{Li}$, Wang, Chen, Chai, \& Tang, 2015). The perceived prevalence of an unhealthy diet was significantly lower in the Oromia and SNNP than the other regions. This variation might be attributed to the fact that Oromia and SNNP regions are naturally rich in plant and vegetable resources, including fruit and vegetables. The higher perceived prevalence of lack of physical exercise in Addis Ababa followed by the Amhara region compared to the other regions could be due to these areas being the most urbanized areas of Ethiopia, resulting in more inactive lifestyles. This finding is consistent with a study in Nepal, which indicated that urbanization contributed to a reduction in physical exercise (Vaidya \& Krettek, 2014). The perceived prevalence of hypertension and tobacco use were higher in Benishangul Gumuz than other regions, which could be ascribed to the cultural and societal norm favoring the use of tobacco, salt, alcohol and raw animal meat.

Overall, the results of this study is consistent with survey studies in India (Mote, 2016), China (Li et al., 2015), and Cameroon (Kufe, Ngufor, Mbeh, \& Mbanya, 2016) which showed regional disparities on the prevalence of NCDs risk factors. These could be associated with the demographics, lifestyle, cultural and social norms, geographic variations and religious influences of a specific region.

\section{Conclusion}

The findings of this study showed considerable agreement in the ranking of the main NCDs, as well as in the perceived prevalence and regional distribution of NCDs risk factors among the different regions of Ethiopia. Ethiopia is characterized by considerable ethnic, religious and culture diversity, as well as a range of dietary habits, lifestyles, health beliefs and awareness, illustrating the need to establish specific strategies for effective NCDs risk factor interventions that accommodates this variety. Regionally appropriate health education is needed, particularly on the benefits of physical exercise, healthy diet habits, and roots of hypertension, blood glucose and the negative health effects of tobacco and alcohol use. To establish regionally specific NCDs risk factor interventions, identifying future illness patterns are essential to assist policy makers to allocate resources and execute strategies. Further population based studies are required to determine the burden of NCDs risk factors and take preventive actions at regional level.

\section{Authors' Contributions}

The authors contributed equally.

\section{Aknowledgements}

We would like to thank all the participants of this study who devoted their precious time and responded to the study questions.

\section{Competing Interests Statement}

We declar that there is no competing interest regarding the publication of this manuscript.

\section{References}

Abebe, S. M., Berhane, Y., Worku, A., \& Getachew, A. (2015). Prevalence and associated factors of hypertension: A crossectional community based study in Northwest Ethiopia. PLoS ONE, 10(4), 1-11. https://doi.org/10.1371/journal.pone.0125210

Amireault, S., Godin, G., \& Vézina-Im, L.-A. (2013). Determinants of physical activity maintenance: a systematic review and meta-analyses. Health Psychology Review, 7(1), 55-91. https://doi.org/10.1080/17437199.2012.701060

Angaw, K., Dadi, A. F., \& Alene, K. A. (2015). Prevalence of hypertension among federal ministry civil servants in Addis Ababa, Ethiopia: a call for a workplace-screening program. BMC Cardiovascular Disorders, 15(1), 76. 
https://doi.org/10.1186/s12872-015-0062-9

Anteneh, Z., Awoke, W., \& Birhanu, D. (2015). Prevalence and correlation of hypertension among adult population in Bahir Dar city, northwest Ethiopia: a community based cross-sectional study. International Journal of General Medicine, 175. https://doi.org/10.2147/IJGM.S81513

Anuwer, R., Seifu, Fromsa, M., Gelaw, Kefale, B., Gunasekaran, T., ... Ahmed. (2015). Medication in ambulatory hypertensive patients in Adama referral hospital. Indo American Journal of Pharmaceutical Research, 5(3).

Asgedom, S. W., Gudina, E. K., \& Desse, T. A. (2016). Assessment of blood pressure control among hypertensive patients in Southwest Ethiopia. PLoS ONE, 11(11), 1-12. https://doi.org/10.1371/journal.pone.0166432

Atiim, G. A., \& Elliott, S. J. (2016). The Global Epidemiologic Transition : Noncommunicable Diseases and Emerging Health Risk of Allergic Disease in Sub-Saharan Africa. Health Education \& Behavior, 43(15), 37S-55S. https://doi.org/10.1177/1090198115606918

Bhattacherjee, S., Datta, S., Roy, J. K., \& Chakraborty, M. (2015). A Cross-sectional Assessment of Risk Factors of Non-Communicable Diseases in a Sub-Himalayan Region of West Bengal, India Using who Steps Approach. The Journal of the Association of Physicians of India, 63(12), 34-40. http://www.ncbi.nlm.nih.gov/pubmed/27666902

Chaker, L., Falla, A., van der Lee, S. J., Muka, T., Imo, D., Jaspers, L., ... Franco, O. H. (2015). The global impact of non-communicable diseases on macro-economic productivity: a systematic review. European Journal of Epidemiology, 30(5), 357-395. https://doi.org/10.1007/s10654-015-0026-5

Chhaya, J., Devalia, J., \& Kedia, G. (2015). Prevalence of Risk Factors and its Association with Non-Communicable Disease among the Faculty Members of Teaching Institute of Ahmedabad City, Gujarat: A Cross-Sectional Study. International Journal of Scientific Study, 3(8), 159-162. https://doi.org/10.17354/ijss/2015/531

Duncan, M., Vandelanotte, C., Kolt, G. S., Rosenkranz, R. R., Caperchione, C. M., George, E. S., ... Mummery, W. K. (2014). Effectiveness of a web- and mobile phone-based intervention to promote physical activity and healthy eating in middle-Aged males: Randomized controlled trial of the manup study. Journal of Medical Internet Research, 16(6), 1-21. https://doi.org/10.2196/jmir.3107

Goodman, A., Sahlqvist, S., \& Ogilvie, D. (2014). New walking and cycling routes and increased physical activity: One- and 2-year findings from the UK iConnect study. American Journal of Public Health, 104(9), 38-46. https://doi.org/10.2105/AJPH.2014.302059

Gudina, K., Bonsa, F., Gudina, E. K., \& Hajito, K. W. (2014). Original article prevalence of hypertension and associated factors in Bedele town, southwest Ethiopia. Ethiopian Journal of Health Science., 24(6), 21-26. https://doi.org/10.1186/s12872-015-0062-9

Helelo, T. P., Gelaw, Y. A., \& Adane, A. A. (2014). Prevalence and Associated Factors of Hypertension among Adults in Durame. International Journal of Public Health Science, 5(4), 1-9. https://doi.org/10.1371/journal.pone.0112790

Hou, X., Anderson, I., \& Burton-Mckenzie, E.-J. (2017). Health and non-communicable diseases: Pacific Possible.

Kavishe, B., Biraro, S., Baisley, K., Vanobberghen, F., Kapiga, S., Munderi, P., ... Grosskurth, H. (2015). High prevalence of hypertension and of risk factors for non-communicable diseases (NCDs): a population based cross-sectional survey of NCDS and HIV infection in Northwestern Tanzania and Southern Uganda. BMC Medicine, 13(1), 126. https://doi.org/10.1186/s12916-015-0357-9

Kraja, F., Kraja, B., Mone, I., Harizi, I., Babameto, A., \& Burazeri, A. (2016). Self-reported Prevalence and Risk Factors of Non-communicable Diseases in the Albanian Adult Population. Medical Archives, 70(3), 208-212. https://doi.org/10.5455/medarh.2016.70.208-212

Kufe, N. C., Ngufor, G., Mbeh, G., \& Mbanya, J. C. (2016). Distribution and patterning of non-communicable disease risk factors in indigenous Mbororo and non-autochthonous populations in Cameroon: cross sectional study. BMC Public Health, 16(1188). https://doi.org/10.1186/s12889-016-3837-8

Li, R., Wang, D., Chen, J., Chai, J., \& Tang, M. (2015). Regional Differences in Smoking, Drinking , and Physical Activities of Chinese Residents. Asia-Pacific Journal of Public Health, 27(2), 230-139. https://doi.org/10.1177/1010539512437604

Lloyd-Sherlock, P., Beard, J., Minicuci, N., Ebrahim, S., \& Chatterji, S. (2014). Hypertension among older adults 
in lowand middle-income countries: Prevalence, awareness and control. International Journal of Epidemiology, 43(1), 116-128. https://doi.org/10.1093/ije/dyt215

Misganaw, A., Mariam, D. H., Araya, T., \& Ayele, K. (2012). Patterns of mortality in public and private hospitals of Addis Ababa, Ethiopia. BMC Public Health, 12(1), 1007. https://doi.org/10.1186/1471-2458-12-1007

Mondo, C. K., Otim, M. A., Akol, G., Musoke, R., \& Orem, J. (2013). The prevalence and distribution of non-communicable diseases and their risk factors in Kasese district, Uganda: cardiovascular topics. Cardiovascular Journal of Africa, 24(3), 52-57. https://doi.org/10.5830/CVJA-2012-081

Mote, B. N. (2016). A regional epidemiology of India' s “ NCD's risk factors " focusing particularly on Maharashtra: A call for "Health promotion " once again. International Journal of Medicine of Public Health, 6(1), 26-30. https://doi.org/10.4103/2230-8598.179756

Peykari, N., Hashemi, H., Dinarvand, R., Haji-Aghajani, M., Malekzadeh, R., Sadrolsadat, A., ... Larijani, B. (2017). National action plan for non-communicable diseases prevention and control in Iran; a response to emerging epidemic. Journal of Diabetes \& Metabolic Disorders, 16(1), 3. https://doi.org/10.1186/s40200-017-0288-4

Raghavendra Swamy Koppad, G. H. O. (2014). Original Article a Community Based Study on the Prevalence of Behavioral Risk Factors of Non-Communicable Diseases in Davangere City. Journal of Evolution of Medical and Dental Science, 3(8), 1841-1849. https://doi.org/10.14260/jemds/2014/2067

Vaidya, A., \& Krettek, A. (2014). Physical activity level and its sociodemographic correlates in a peri-urban Nepalese population : a cross-sectional study from the Jhaukhel-Duwakot health demographic surveillance site. International Journal of Behavioral Nutrition and Physical Activity, 11(39), 1-12. https://doi.org/10.1186/1479-5868-11-39

World Health Organization (WHO). (2013). WHO Country Cooperation Strategy 2012-2015 Ethiopia. Retrieved from http://www.who.int/countryfocus/cooperation_strategy/ccs_khm_en.pdf?ua $=1$

Wondemagegn, HBizuayehu, Abie, Ayalneh, \& Tiruye. (2017). Undiagnosed diabetes mellitus and related factors in East Gojjam (NW Ethiopia) in 2016: A community-based study. Journal of Public Health Research, 6(1), 18-23. https://doi.org/10.4081/jphr.2017.834

World Health Organization (WHO). (2014). Non communicable Diseases Country Profiles. Retrieved from https://doi.org/10.1111/jgs.12171

Zaman, M. M., Bhuiyan, M. R., Karim, M. N., MoniruzZaman, Rahman, M. M., Akanda, A. W., \& Fernando, T. (2015). Clustering of non-communicable diseases risk factors in Bangladeshi adults: An analysis of STEPS survey 2013. BMC Public Health, 15(1), 659. https://doi.org/10.1186/s12889-015-1938-4

Zhang, Y. (2014). Patterns of risk factors related to non-communicable diseases ( NCDs ) in Asian and Oceania countries by using cluster analysis. Journal of International Health, 19(4), 257-265.

\section{Copyrights}

Copyright for this article is retained by the author(s), with first publication rights granted to the journal.

This is an open-access article distributed under the terms and conditions of the Creative Commons Attribution license (http://creativecommons.org/licenses/by/4.0/). 